\title{
Palladium-catalyzed carbocyclization/cross-coupling reactions of two different allenic moieties: Synthesis of 3-(buta-1,3-dienyl) carbazoles and mechanistic insights
}

\author{
Benito Alcaide, ${ }^{* a}$ Pedro Almendros, ${ }^{b}{ }^{b} J_{\text {osé }}$ M. Alonso, ${ }^{a}$ and Israel Fernández ${ }^{c}$ \\ ${ }_{5}$ Received (in $\left.X X X, X X X\right) X$ th $X X X X X X X X X 20 X X$, Accepted Xth $X X X X X X X X X 20 X X$ \\ DOI: $10.1039 / b 000000 x$
}

A palladium-catalyzed chemo-, regio- and stereoselective carbocyclization/cross-coupling sequence of two different $\alpha$ allenols to afford 3-(E-buta-1,3-dienyl) carbazoles is reported.

10 Allenes are versatile synthetic intermediates in organic synthesis. ${ }^{1,2,3}$ However, the reported work involving the use of two different allenes, was limited to oxycyclization/crosscoupling reactions; ${ }^{4}$ being missed the carbocyclization/crosscoupling sequence. We report herein a controlled 15 carbocyclization/cross-coupling domino reaction of indoletethered allenols and $\alpha$-allenic esters for the direct preparation of the chemically and biologically relevant carbazole nucleus.

The structure of starting materials for the carbocycle formation, arene-tethered allenols $\mathbf{1}^{5}$ suggests at least two 20 possibilities for reactivity, namely, C-cyclization versus Ocyclization. ${ }^{6}$ Disappointingly, upon treating the benzene-tethered allenol 1a with $\alpha$-allenic acetate $\mathbf{2 a}$ at room temperature with 5 mol\% $\mathrm{PdCl}_{2}$ in DMF, it was found that the 2,5-dihydrofuran 3a arising from a heterocyclization/cross-coupling process was 25 formed in $59 \%$ yield (Scheme 1). ${ }^{7}$ In an attempt to improve the carbocyclization efficiency under similar reactions conditions, we screened a different aromatic allenol system such as indoletethered allenol $\mathbf{1 b}$ on reacting with $\alpha$-allenic acetate $\mathbf{2 a}$. Interestingly, not the 2,5-dihydrofuran $\mathbf{3 b}$ but the benzo30 annelation adduct, ${ }^{8}$ carbazole $\mathbf{4 a}$, was exclusively obtained (Scheme 1), resulting in failure the carbocyclization/crosscoupling sequence because the cross coupling step was missed.

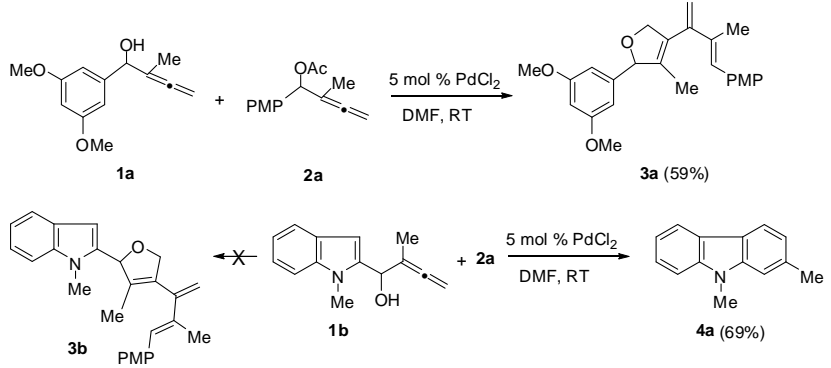

Scheme $\mathbf{1}$ Divergent cyclization reactions of allenols $\mathbf{1 a}$ and $\mathbf{1 b}$ under 35 palladium catalysis. $\mathrm{PMP}=4-\mathrm{MeOC}_{6} \mathrm{H}_{4}$.

Attempts of the domino reaction using $\mathrm{Pd}(\mathrm{OAc})_{2}$ and $\left[\mathrm{Pd}\left(\mathrm{PPh}_{3}\right)_{4}\right]$ also failed. The use of additives, such as $\mathrm{K}_{2} \mathrm{CO}_{3}$, $\mathrm{FeCl}_{3}$, and $\mathrm{PPh}_{3}$ did not show any appreciable difference. Apparently, allenol derivatives $\mathbf{1 b}$ and $\mathbf{2 a}$ have inadequate
40 reactivity for the joint participation in the coupling process. Fortunately, an interesting and useful temperature effect next emerged from the observation that the simple heating at $80^{\circ} \mathrm{C}$ resulted in the formation of the desired carbocyclization/crosscoupling adduct $\mathbf{5 a}$ in a reasonable $71 \%$ yield (Scheme 2). The 45 overall transformation can be roughly explained invoking a 6endo-trig allene carbocyclization followed by cross-coupling and final dehydration. Thus, it is possible to suppress the formation of the cycloisomerization/dehydration adduct by performing the reaction at higher temperature, yielding carbazole $\mathbf{5 a}$ as the 50 exclusive product. ${ }^{9}$ A general trend can be deduced on the basis of these results: carbazole $\mathbf{4 a}$ is the kinetic control product while carbazole 5a is the thermodynamic control product. We applied this protocol to the generation of different carbazoles $\mathbf{5 b}-\mathbf{i}$ by the successfully use of variously substituted allenic esters $\mathbf{2 b}-\mathbf{i}$ ${ }_{55}$ (Scheme 2). We also decided to undertake a study of the potential use of more diverse allenols $\mathbf{1}$ in this novel reaction. The palladium-catalyzed carbocyclization/cross-coupling sequence of hindered phenyl-substituted indole-tethered allenol 1c failed. By contrast, non-substituted allenol 1d efficiently reacted to afford 60 the corresponding 3-(buta-1,3-dienyl) carbazole 5k (Scheme 2). Importantly, all products were obtained as single isomers, that is, with complete $E$ selectivity with regard to the newly established $\mathrm{C}=\mathrm{C}$ double bond, as determined by qualitative homonuclear NOE difference spectra.

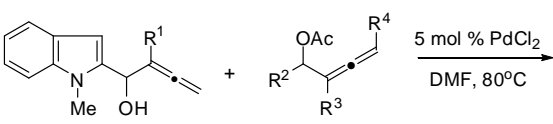

$$
\begin{aligned}
& \text { 1b } R^{1}=\text { Me } \quad 2 a R^{2}=4-\mathrm{OMeC}_{6} \mathrm{H}_{4}, \mathrm{R}^{3}=\mathrm{Me}, \mathrm{R}^{4}=\mathrm{H} \\
& \text { 1b } R^{1}=M e \quad 2 b R^{2}=4-M e C_{6} H_{4}, R^{3}=M e, R^{4}=H \\
& \text { 1b } R^{1}=M e \quad 2 c R^{2}=4-B r C_{6} H_{4}, R^{3}=M e, R^{4}=H \\
& \text { 1b } \mathrm{R}^{1}=\mathrm{Me} \quad 2 \mathrm{~d} \mathrm{R} \mathrm{R}^{2}=\mathrm{C}_{6} \mathrm{H}_{5}, \mathrm{R}^{3}=\mathrm{Me}, \mathrm{R}^{4}=\mathrm{H} \\
& \text { 1b } R^{1}=M e \quad 2 e R^{2}=4-M_{e} M_{6} H_{4}, R^{3}=H, R^{4}=H \\
& \text { 1b } R^{1}=\mathrm{Me} \quad \text { 2f } \mathrm{R}^{2}=\mathrm{C}_{6} \mathrm{H}_{5}, \mathrm{R}^{3}=\mathrm{H}, \mathrm{R}^{4}=\mathrm{H} \\
& \text { 1b } \mathrm{R}^{1}=\mathrm{Me} \quad 2 \mathrm{~g} \mathrm{R}^{2}=\mathrm{H}, \mathrm{R}^{3}=\mathrm{H}, \mathrm{R}^{4}=n \mathrm{C}_{3} \mathrm{H}_{7} \\
& \text { 1b } R^{1}=M e \quad 2 h R^{2}=H, R^{3}=H, R^{4}=t C_{4} H_{9} \\
& \text { 1b } \mathrm{R}^{1}=\mathrm{Me} \quad \text { 2i } \mathrm{R}^{2}=\mathrm{H}, \mathrm{R}^{3}=\mathrm{H}, \mathrm{R}^{4}=\mathrm{C}_{6} \mathrm{H}_{5} \\
& \text { 1c } R^{1}=P h \quad 2 a R^{2}=4-\mathrm{OMeC}_{6} \mathrm{H}_{4}, \mathrm{R}^{3}=\mathrm{Me}, \mathrm{R}^{4}=\mathrm{H} \\
& 1 d R^{1}=H \quad 2 a R^{2}=4-O_{M e C} H_{4}, R^{3}=M e, R^{4}=H
\end{aligned}
$$

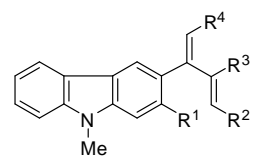

5a $(71 \%)$

$5 \mathbf{b}(60 \%)$

$5 c(47 \%)$

$5 d(63 \%)$

5 e $(63 \%)$

$5 \mathbf{f}(67 \%)$

5 g $(58 \%)$

5 h $(40 \%)$

$5 i(63 \%)$

5j $(0 \%)$

5 k $(59 \%)$

Scheme 2 Synthesis of 3-(buta-1,3-dienyl) carbazoles $\mathbf{5}$ through carbocyclization/cross coupling reactions of allenol derivatives $\mathbf{1}$ and $\mathbf{2}$ under palladium catalysis at $80^{\circ} \mathrm{C}$.

A possible pathway for the palladium-catalyzed generation of 70 functionalized carbazoles $\mathbf{5}$ is outlined in Scheme 3. Initial Pd(II)coordination to the 1,2-diene moiety leads to the allenepalladium 
complex $\mathbf{1 b}, \mathbf{d}-\mathrm{PdCl}_{2}$. Species $\mathbf{1 b}, \mathbf{d}-\mathrm{PdCl}_{2}$ suffers an intramolecular chemo- and regioselective 6-endo-trig carbocyclization reaction to produce the palladadihydrocarbazole 6. Loss of $\mathrm{HCl}$ with concurrent dehydration under the reaction 5 conditions produces aryl palladium intermediate $\mathbf{8}$. The coupling of intermediate palladacarbazole $\mathbf{8}$ with $\mathbf{2}$ leading to species $\mathbf{1 3}$ takes place regioselectively at the central allene carbon atom of $\mathbf{2}$. Finally, a trans- $\beta$-deacetoxypalladation generates, in a highly stereoselective manner, 3-(buta-1,3-dienyl) carbazoles $\mathbf{5}$ as single $10 E$-isomers with concomitant regeneration of the $\mathrm{Pd}(\mathrm{II})$ species. Worthy of note, the carbopalladation of carbazolyl palladium intermediate $\mathbf{8}$ to form the corresponding $\pi$-allylic palladium intermediate is totally chemoselective towards the allenic acetate $\mathbf{2}$ since homodimerization from the coupling with other molecule 15 of free allenol $\mathbf{1 b}$ did not occur.

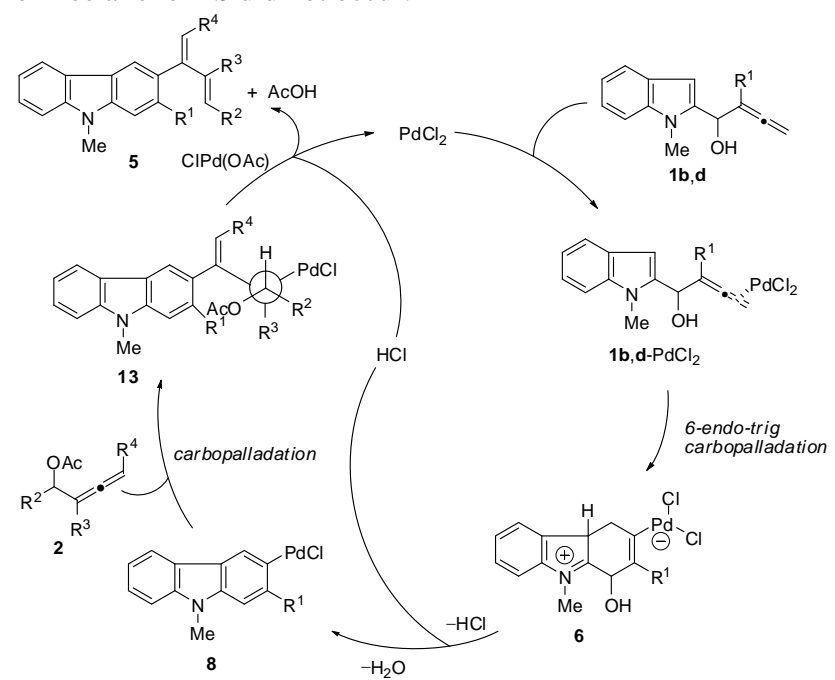

Scheme 3 Mechanistic explanation for the palladium-catalyzed preparation of 3-(buta-1,3-dienyl) carbazoles 5.

To gain more insight into the reaction mechanisms of the 20 above palladium-catalyzed cyclization reactions, a computational (DFT) study was carried out. ${ }^{10}$ First, we computed the experimentally observed preference of allenol 1b towards the carbocyclization reaction in the presence of $\mathrm{PdCl}_{2}$ (Scheme 1). As readily seen in Figure 1, it can be concluded that the initially 25 formed allenepalladium complex $\mathbf{1 b}-\mathbf{P d}$ is completely transformed into dihydrocarbazole $\mathbf{6}$ via the saddle point TS1. This extraordinary regioselectivity takes place under both kinetic and thermodynamic control, in view of the higher activation energy required for the formation of dihydrofuran $6^{\prime}\left(\Delta \Delta \mathrm{G}^{\neq}{ }_{298}=\right.$ $305.2 \mathrm{kcal} / \mathrm{mol})$, as well as the considerably lower reaction energy computed for cycloadduct $6\left(\Delta \Delta \mathrm{G}_{\mathrm{R}, 298}=16.6 \mathrm{kcal} / \mathrm{mol}\right)$. Subsequent loss of $\mathrm{HCl}$ (which produces intermediate 7) and $\mathrm{H}_{2} \mathrm{O}$ leads to aromatic carbazole $\mathbf{8}$, a palladium(II) complex able to react with the second allenic moiety.

35 Palladacarbazole $\mathbf{8}$ is then transformed into the final carbazole 4a via protonolysis of the carbon-palladium bond mediated by $\mathrm{HCl}$. Our calculations (Figure 2) suggest that this step starts from complex 10, where the $\mathrm{HCl}$ is weakly bonded to the transition metal, which easily evolves to complex 12 through the saddle 40 point TS2 (activation barrier of only $2.7 \mathrm{kcal} / \mathrm{mol}$ ) in an exergonic process $\left(\Delta \mathrm{G}_{\mathrm{R}, 298}=-17.6 \mathrm{kcal} / \mathrm{mol}\right)$. Subsequent decoordination of $\mathrm{PdCl}_{2}$ will form the observed carbazole $\mathbf{4 a}$. Interestingly, complex 8 can also coordinate a new allene ligand (model allene $\mathbf{9}$ in the calculations) to produce the 45 allenepalladium complex 11. This species evolves to complex $\mathbf{1 3}$ via the transition state TS3, a saddle point associated with the new carbon-carbon bond formation. From the data in Figure 2, this step is kinetically disfavored respect to the above-mentioned C-Pd protonolysis $\left(\Delta \Delta \mathrm{G}^{\neq}{ }_{298}=9.7 \mathrm{kcal} / \mathrm{mol}\right)$ but 50 thermodynamically favored $\left(\Delta \Delta \mathrm{G}_{\mathrm{R}, 298}=5.4 \mathrm{kcal} / \mathrm{mol}\right)$. This finding strongly supports our hypothesis that carbazole $\mathbf{4 a}$, derived from complex 12, is the kinetically-controlled product whereas carbazoles 5, derived from complex 13, are thermodynamically favored.

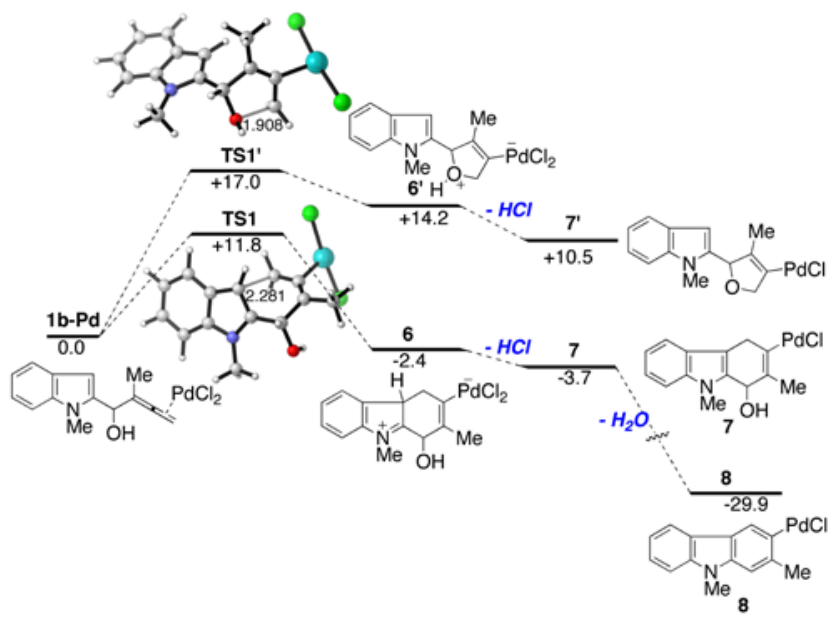

Figure 1 Computed reaction profile of allenepalladium complex $\mathbf{1 b}-\mathbf{P d}{ }^{11}$

The process leading to carbazoles $\mathbf{5}$ ends with the easy rotation about the $\mathrm{C}-\mathrm{C}$ bond in complex 13, which can produce two different complexes, 14-trans and 14-cis. These species possess 60 the adequate geometry to undergo the final deacetoxypalladation reaction via the corresponding saddle points TS4-trans and TS4cis, respectively. Strikingly, the trans-deacetoxypalladation reaction (via TS4-trans) is kinetically $\left(\Delta \Delta \mathrm{G}^{\neq}{ }_{298}=2.2 \mathrm{kcal} / \mathrm{mol}\right)$ and thermodynamically favored over the analogous cis-process 65 (via TS4-cis). This justifies the complete stereoselectivity of the transformation which exclusively produces 3-(buta-1,3-dienyl) carbazoles 5 as single $E$-isomers. This step, albeit exergonic occurs with the highest activation barrier $\left(\Delta \mathrm{G}^{\neq}{ }_{298}=19.7\right.$ $\mathrm{kcal} / \mathrm{mol}$ ) computed for the entire reaction profile, and therefore 70 constitutes the bottle-neck of the transformation. Furthermore, this finding explains why a high temperature is experimentally required to produce carbazoles $\mathbf{5}$ (easily formed by decoordination of $\mathrm{ClPd}(\mathrm{OAc})$ in complex 15). Finally, the $\mathrm{PdCl}_{2}$ catalyst is regenerated by protonolysis of the released $\mathrm{ClPd}(\mathrm{OAc})$ 75 complex with $\mathrm{HCl}$ (computed activation barrier of $8.2 \mathrm{kcal} / \mathrm{mol}$ ) forming AcOH as reaction product as well.

We have also computed the corresponding 11 to $\mathbf{1 3}$ reaction for the unprotected $\alpha$-hydroxyallene (denoted as 11bis to 13bis). Not surprisingly, the more nucleophilic free $\mathrm{OH}$ of the allene can 80 coordinate the metal center thus stabilizing the initial complex 11bis. This is translated into a higher activation barrier via TS3bis compared to the reaction involving TS3 via the OAccomplex 11, where the OAc cannot coordinate the metal and acts as a mere spectator in this $\mathrm{C}-\mathrm{C}$ bond formation process (Figure 853 ). Moreover, the OAc is essential in the final step of the process because it helps to release the initial catalyst through the formation of the $\mathrm{ClPd}(\mathrm{OAc})$ complex. Obviously, the 
corresponding complex formed with the $\mathrm{OH}$ (with only one possibility of coordination) would be thermodynamically less stable thus leading to a more difficult release of the initial Pd catalyst.

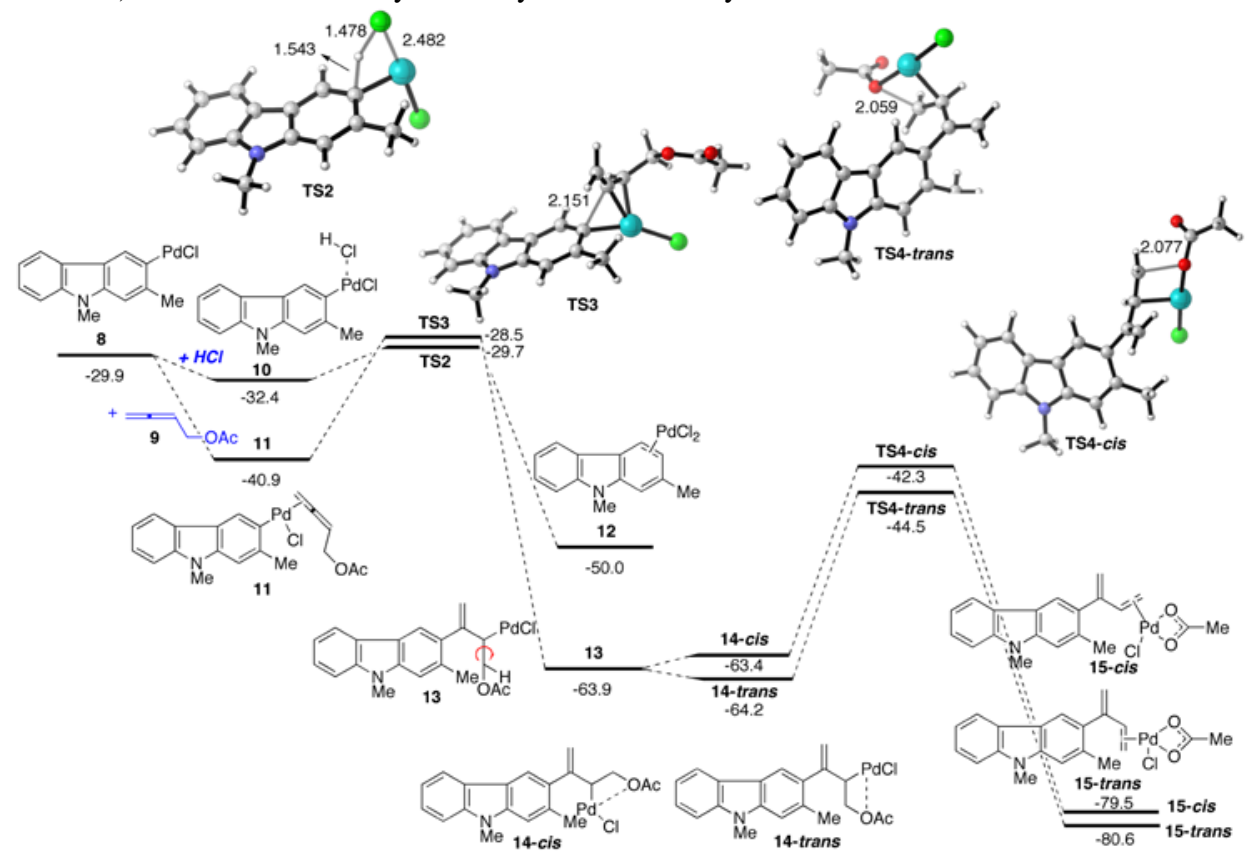

Figure 2 Computed reaction profile of complex 8 to produce complexes 12 and $15 .{ }^{11}$

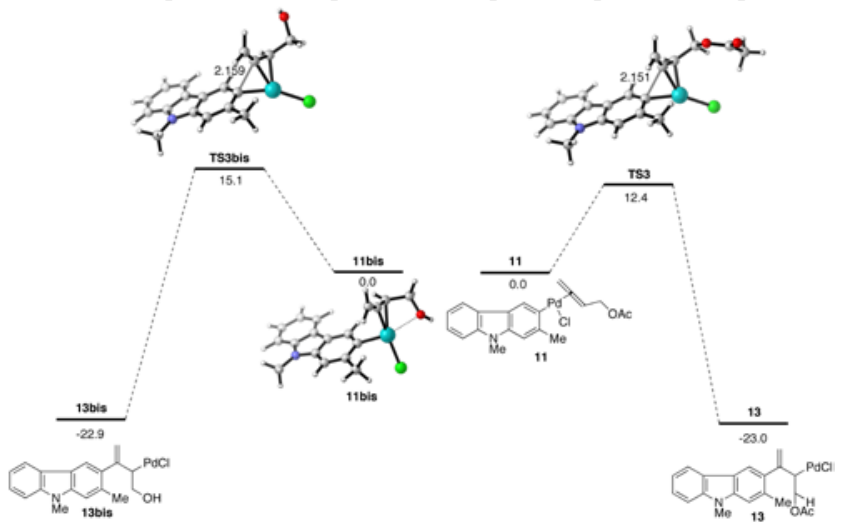

Figure 3 Computed reaction profile of $\alpha$-hydroxyallene 11 bis to produce carbazole 13bis. $^{11}$

10 In conclusion, a combined experimental and computational study of a palladium-catalyzed synthetic route to 3-(E-buta-1,3-dienyl) carbazoles from two different $\alpha$-allenols has been accomplished.

Acknowledgment. Support for this work by the MICINN [CTQ2009-09318, CTQ2010-20714-C02-01, and Consolider15 Ingenio 2010 (CSD2007-00006)], CAM (Projects S2009/PPQ1752 and S2009/PPQ-1634), UCM-Santander (Grant GR35/10A) are gratefully acknowledged. I.F. is a Ramón y Cajal fellow.

\section{Notes and references}

${ }^{a}$ Grupo de Lactamas y Heterociclos Bioactivos, Departamento de 20 Química Orgánica, Unidad Asociada al CSIC, Facultad de Química, Universidad Complutense de Madrid, 28040-Madrid, Spain. Fax: +34 91-3944103; E-mail: alcaideb@quim.ucm.es

${ }^{b}$ Instituto de Química Orgánica General, IQOG, CSIC, Juan de la Cierva

3, 28006-Madrid, Spain. Fax: +34 91-5644853; E-mail:

25 Palmendros@iqog.csic.es
${ }^{c}$ Departamento de Química Orgánica, Facultad de Química, Universidad Complutense de Madrid, 28040-Madrid, Spain

$\dagger$ Electronic Supplementary Information (ESI) available: Experimental procedures, characterization data of new compounds, and copies of NMR 30 spectra. See DOI: 10.1039/b000000x/

1 N. Krause and C. Winter, Chem. Rev., 2011, 111, 1994.

2 (a) A. S. K. Hashmi, A. M. Schuster, S. Litters, F. Rominger and M. Pernpointner, Chem. Eur. J., 2011, 17, 5661; (b) S. Kim and P. H. Lee, Adv. Synth. Catal., 2008, 350, 547; (c) C. Deutsch, B. H.

$35 \quad$ Lipshutz and N. Krause, Angew. Chem. Int. Ed., 2007, 46, 1677.

3 (a) B. Gockel and N. Krause, Org. Lett., 2006, 8, 4485; (b) C. Deutsch, B. Gockel, A. Hoffmann-Röder and N. Krause, Synlett 2007, 1790.

4 For an overview, see: B. Alcaide, P. Almendros and T. Martínez del 40 Campo, Chem. Eur. J., 2010, 16, 5836.

5 Allenols 1 were readily prepared in good yield using our previously described methodology: (a) B. Alcaide, P. Almendros, C. Aragoncillo and M. C. Redondo, Eur. J. Org. Chem., 2005, 98; (b) B. Alcaide, P. Almendros, C. Aragoncillo and M. C. Redondo, Chem. 45 Commun., 2002, 1472.

6 Besides, regioselectivity problems (endo versus exo cyclization) are usually encountered in allene chemistry.

7 (a) A. S. K. Hashmi, Angew. Chem. Int. Ed. Engl., 1995, 34, 1581; (b) B. Alcaide, P. Almendros and T. Martínez del Campo, Angew. 50 Chem. Int. Ed. 2006, 45, 4501.

8 (a) A. S. K. Hashmi, W. Yang and F. Rominger, Angew. Chem. Int. Ed. Engl., 2011, 50, 5762. (b) B. Alcaide, P. Almendros, J. M. Alonso, M. T. Quirós and P. Gadziński, Adv. Synth. Catal., 2011, 353, 1871.

${ }_{55} 9$ 3-(Buta-1,3-dienyl)-9-alkyl-carbazoles have been designed as pharmacophores that induce post-differentiation apoptosis in acute promyelocytic leukemia cells: D. Ivanova, H. Gronemeyer and A. R. de Lera, ChemMedChem, 2011, 6, 1518.

10 All calculations were carried out at the B3LYP/def2-SVP level. See 60 computational details in the supporting information.

11 Relative free energy values (computed at $298 \mathrm{~K}$ ) and bond distances are given in $\mathrm{kcal} / \mathrm{mol}$ and angstroms, respectively. All data have been computed at the B3LYP/def2-SVP level. 


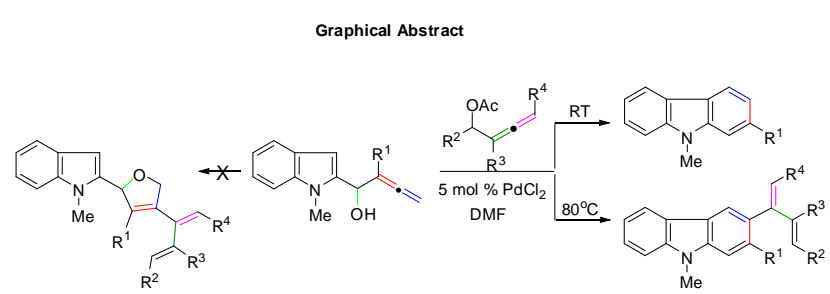

An efficient palladium-catalyzed synthetic route to 3-(E-buta-1,3-dienyl) carbazoles from two different alfaallenols has been reported. The reaction was found to proceed with complete control of product chemo-, regioand stereoselectivity through a carbocyclization/cross-coupling sequence. The mechanism of this process has product whereas buta-13-dienylcarbazoles are thermodynamically favored.

Autores: Alcaide, B.; Almendros, P.; Alonso, J. : M.; Fernández, I.

Título: Palladium-Catalyzed Carbocyclization/Cross-Coupling Reactions of Two Different Allenic Moieties: Synthesis of 3${ }_{10}$ (Buta-1,3-dienyl)carbazoles and Mechanistic Insights

Revista: Chem. Commun. 2012, 48, 6604-6606 